\title{
PROJECT DECODE: SCHOOLING THROUGH THE LENS OF LESS- MOTIVATED STUDENTS
}

\author{
John B. Visillas \\ Dr. John B. Visillas, Panabo City National High School, Philippines, john.visillas@deped.gov.ph
}

\begin{abstract}
Students are expected to participate in classroom activities and to be fully engaged in teaching and learning processes. A deviation of this expectation can lead to a conclusion that a student is less motivated to learn the lesson. However, the researcher is very much interested to discover the real reasons why some students are disengaged in classroom processes that lead to the inquiry of this phenomenological investigation. There were ten (10) Grade 10 student-participants for the focus group discussion and ten (10) Grade 12 students for the in-depth interview.

A purposive sampling technique was utilized in this study. After careful analysis of the responses of the participants, the following themes emerged: Security for a Better Future; and Significant Others which are both motivating views of students about schooling. However, there were demotivating themes that emerged from this study which include the following: Personal Issues such as lack of sleep, home issues, mental ability, and difficulty in English as a medium of instruction; Unfriendly Learning Environment in School and Teacher Qualities. By fully understanding the themes discussed, teachers, administrators, and the officials of the Department of Education of Panabo City Division will have a better understanding of those students who are branded as less-motivated learners. School administration may adopt some intervention programs to address the issues of students. Hopefully, they will take appropriate action in the delivery of the curriculum to improve the participation of students in the classroom processes.
\end{abstract}

Keywords: student's voice; student's difficulty in schooling, struggles in schooling

\section{INTRODUCTION}

I think we do need to look through student's eyes there by building bridges between their understanding and the concepts and skills most likely to advance theiropportunities. But the only way we can truly begin to look through student's eyes is to reject thenotion that our own view of the world is always right.

(Ellwood, 1993,p.77)

Teachers are always encouraged to be creative, passionate enthusiastic and innovative for them to be effective in developing students readiness to live in the $21^{\text {st }}$ century. However, in reality, no matter how much effort teachers have given, some students show less motivation and interest to learn.

Teaching in the lower sections is challenging for every teacher. Unlike with their counterparts who are teaching in Science Technology and Engineering (STE) Program, in first sections of the Basic Education 
Curriculum (BEC) and Special Education in the Arts (SPA) curriculum. Each day is a struggle for them on how to bring the best from their students, most especially those who don't bother to pass the subject or not. They sometimes cut classes, submit their project late, manifest absenteeism and tardiness and have poor quality on the required output.

The DepEd policy "No Child Left Behind" encourages every school administrator and teacher to provide educational services and assistance to students with the hope that they will be able to acquire the learning competencies of every subject. However, not all students are highly motivated to learn. This becomes a problem by some teachers. With the aforementioned DepEd policy, every student is important. Thus, there is a need to determine why some students are less motivated in their studies so that necessary programs, projects orany intervention will be created and implemented in solving this perennial problem in school. The purpose of this investigation was to determine how the students perceive schooling that might be the reason for their behavior and to discover other factors that causethem to be less engaged inside the classroom.

The findings of this study helped the curriculum-makers, teachers, the school and the Department of Education to make necessary revisions and adjustments in the delivery of the curriculum. Since the students are the focus of education, it is appropriate to consider how they view schooling. Since they are the recipients of all the programs of the Department of Education, the receiver of all innovations implemented by the Department, it is appropriate that their voice will be heard so that their educational needs will be met. Hence, teachers, school administrators and DepEd as a wholewill be able to design and implement programs that may solve the dilemma anchoring from the voice of the students - the end product of education.

\subsection{Literature Review}

\subsubsection{Perception Affects One's View}

Meriam-Webster defined perception as the result of perceiving or observation. It is also referred to the mental image or concept. The perceptions we had in any object, thing or situation could affect our emotions and behaviors and our emotional and behavioral reactions also help shape our environments and skew our beliefs of those environments. (Students Perception of School). Thus our behavior is greatly influenced on how we perceive things. We give importance to things if we perceive its value to us and consequently we do not give value to others things when we perceive it does not have value to us. Furthermore, Marzano, (2017) singled out that positive perception attitude affects learning. He stated that without positive attitudes and perceptions, students have little chance of learning proficiently.

In school, there is a need to determine how the students perceive schooling so that the school will be able to give what the students need. Weinstein (1983) emphasized that it is important to teachers to know the world of school from the perspective of the students. This is deemed necessary to harmonize the effort of the teachers to which deem important by the students. The failure of it will result to unsynchronized perception about education. The existence of different perspectives between students and teachers has important implications because perspectives directly influence behavior. As the result of different perspectives, students' learning strategies and teachers' instructional strategies may be in disharmony, thus may lead to dissatisfaction and will result in low motivation.

A study of Nonaka, D. et.al. (2010) entitled "Students' perception of school environment and life satisfaction at Sinhala-medium secondary schools in the Colombo District, Sri Lanka" they found out that students who perceived positive school environment were significantly more likely to have high life satisfaction. Positive changes in the focused areas of school environment have the potential to lead to improved life satisfaction ofstudents. This finding was reinforced by Konings (2007) who also found out that educationally favorable student characteristics such as personal interest in learning are related to high perception and low dissatisfaction. While educationally unfavorable students' characteristics such as motivational problems are related to low perception and high dissatisfaction.

\subsubsection{Student's Perspective Matter}

Murphy (2016) pointed out the problem of ignoring the perspective of students about schooling. First and foremost, he said "students' perspective is often unseen in school." Theyare often unseen because we do not seek them out. We often use students' perspective to reinforce what we have already decided. Second, we inadequately see classroom through the eyes of youngsters, we miss the opportunity to do our job effectively, to improve our skills and knowledge in enhancing meaningful academic challenge, and to create a caring and supportive learning environment. Third, the understanding and wisdom that help us to 
be more effective educators and that provide joy and meaning in our work will be materialized if we seek harder to see the world through the eyes of the students.

In school, programs and projects were implemented with the desire to help and contribute to the development of every student. However, students have fewer opportunities to be heard on what matters to them. Their ideas were not considered as important in the planning, implementing and evaluating the school programs and projects. However, movements have taken place in considering the voice of the students, so that they will be heard (Groves and Welsh 2010). Grove and Welsh further emphasized that students' perceptions related to their learning and school experiences are as valid and important as those of other members of the school community, such as teachers, parents and administrators. Students' perceptions of learning and school and the factors that influence such views are continuously evolving. The most effective means for attaining reliable and valuable information about students' views and the factors that influence these views is to askthe students themselves. Inviting students to express their views about learning and school and the factors they perceive as contributing positively and negatively toward their learning and school experiences assures a more comprehensive description of school effectiveness and learning.

\subsubsection{Related Studies}

There were very few available studies discussing the topic. However, as the researcher gleaned through studies that attempted to discuss the perception of students towards learning, he came across with the study of Groves and Welsh (2010) which discussedabout the view of high school students about learning and school experiences that are deemed important to improve student's learning. Fourteen Year 11 students in Perth Western high schools in Australia were the respondents of the study. The study found out that several factors were seen influential in the learning and school experiences of the students. These factors included students' diverse needs, students' voice, relationship, responsibility andcontrol and teacher relationships. The study confirmed that students can articulate their own learning and school experiences can share their insights and opinion clearly if only then given an opportunity to do so. However, this study failed to categorize perception of high and low performing students that the latter were the focus of the present investigation.

A similar study of Fuberg (2011) entitled "How do students' perceptions of their education change over time?" explored on how student perceptions are distributed over the course of a university education through comparing four key variables with a time frame. These variables are learning, responsibility, engagement and satisfaction. A survey questionnaire was formulated and distributed among students in all levels of the education in Umea University in Sweden. The findings showed that perceptions of learning, responsibility and engagement changed over time while the perception of satisfaction remained constant. On the perception of students towards learning which was similar to the current investigation, the author found out that students perception of learning changes from time to time. Second, the high level students have more mature and wide perception of what learning is compared to their low level counterparts. However, the present investigation was different in terms of the focused participants. The present investigation was focused on high school and less motivated students in public school. Second, the present investigation was a qualitative study which was the recommendation of Fuberg (2011) to understand profoundly their perception towards learning that cannot be determined through quantitative investigation as what he did.

Although there were so many programs implemented to improve the quality of the basic education, this may become futile if the curriculum developers fail to consider the view of these less motivated students towards schooling.

\subsubsection{Research Questions}

This study answered the following questions to attain the purpose of the proposedinvestigation:

1. How do you perceive schooling?

1.1 Is it relevant to your future plans?

1.2 Do you think it helps you to have a better future?

1.3 Does it provide you what you need to live the "real life"?

2. What motivates you to go to school? 
2.1 What inspires you to finish your study?

2.2 What influences you to earn an education?

\subsection{Why you keep going to school?}

3. What discourages you to be actively involved in classroom processes?

2.1 What you don't like in school? (environment, policies, teachers, subject, etc.)

2.2 Are you bored with the lessons? Explain.

2.3 What aspect of schooling you don't like? (medium of instruction, the method ofthe teaching, class activities, content, evaluation, etc. )

\subsubsection{Scope and Limitation}

The study was a qualitative study that sought the perception of low motivated students of Panabo National High School about schooling for the school year $2017-2018$. Theparticipants of the study were the Grade 10 and Grade 12 students. Interview and Focus Group Discussion were the tools for gathering the needed data. The result of the interview and FGD were grouped into themes for analysis of the findings.

\section{METHODS}

\subsection{Research Methodology}

This investigation employed qualitative research method since it focused on describing the perception of less-motivated students towards schooling. The investigation strived to have a deeper understanding of the perception of these students. The needed data to determine the perception of the students could not be done through quantitative type of research since this study did not focus on numbers and figures but to the perception of students towards schooling. Because of these reasons, qualitative method was the appropriate method to be used because it helped the researcher attain 'a glimpse of the world' of the subject being studied (Ospina, 2004); and discover the meanings that participants attached to their behavior, as well as how they interpret situations, and what their perspectives are on particular issues (Pratt, 2006).

\subsection{Sampling}

This study utilized purposive sampling technique. Through the help of the advisers, low motivated students were identified through their attitude toward schooling and class attendance. There were 20 participants in this investigation; ten (10) students for the interview and another 10 students for the Focus Group Discussion (FGD). The students werethe current Grade 10 and 12 students of PNHS. These two groups of students were selected because they were the groups that have strong desire to complete the Junior and Senior HighSchool education.

\subsection{Data Gathering Method}

The primary methods used in gathering the data needed for this study were interview and focus group discussion. In-depth interview was a data collection process in which the researcher asked questions and recorded their answers from only one participant in the study at a time, while focus group interview was the process of collecting data through interviews with a group of people typically four to six (Wichaikul, 2013). These methods were appropriate to get the needed data to determine the perception of the students towards schooling. Interview with the participants was considered as the most widely used for the production of qualitative data (Polkinghorne, 2005). It's because interviews can provide much more detailed information than what is available through other data collection methods, such as surveys (Neale and Boyce 2006).

\subsection{Ethical Issues}

Since the participants were the Grade 10 and 12 students, there was a need to secure necessary permit to conduct the study. The researcher informed the principal about the investigation for approval. He secured parent consent and informed consent for the participants of the interview and focus group discussion. To maintain the privacy of the participants, a pseudonym was used to each of them. 


\subsection{Data Analysis}

Data analysis according to Creswell (2009) is an ongoing process involving continual reflection about the data, asking analytic questions, and writing memos throughout the study. Qualitative data analysis is conducted concurrently with gathering data, making interpretation, and writing reports. This led the researcher analyze the interview collected.

The researcher followed the steps in analyzing the data recommended by Creswell (2009). He organized and prepared data for analysis. This involved transcribing interviews, photocopying of interview materials, encoding field notes or sorting and arranging the data into different parts. He read through all the data to get the general sense of the information and to reflect on its overall meaning. He began his analysis with the coding process. Coding is the process of organizing the materials into chunks of segments of texts before bringing the meaning of information. This involved taking text data or pictures gathered during the data collection, segmenting sentences or image into categories and labeling those categories with aterm, often a term based on the actual language of the participants. Maykut and Morehouse (1994) provided him the technique on how to code the data. It is done by writing in the upperright-hand corner of each page of data, the code for the type of data and the page number of the particular data set such as pages of a transcript. For example, the fifth page (5) of a transcript (T) from an interview with Marie (M) is coded in the top right-hand corner of the page as T/M-5. Coding process was used to generate a description of the setting or people as well as categories of themes for analysis. These themes were used to shape into a general description of the phenomenon being studied. In the end, the themes that emerged from the study were thoroughly discussed to correctly describe the perception of students towards schooling.

\subsection{Results}

This chapter presented the significant findings of the investigation in narrative form. It presented the emerging themes from the primary questions raised for this purpose.

\section{Research Question No. 1: How do you view schooling?}

\section{Theme: Security for Better Future}

The responses of the participants of the study justified their effort in attending their classes despite of the perception of their teachers that they are less motivated to learn the lesson because of their less engagement to teaching-learning process. The participants revealed that they continued going to school although they're not so active in classroom process because they wanted to learn and eventually can provide them with good future.

The behavior seen by the participants are very opposite to their conviction that they have to finish their education to have a better future. As a typical teacher, it is very hard to realize that the less active students in your class have positive view about schooling since teachers regarded students as serious in their studies if they are active in classroom activities. But if the students will do the opposite, teachers may conclude that they are not serious in their studies and may conclude that these students do not value education.

\section{Research Question No. 2: What motivates you to go to school?}

To divulge the real reasons of students why they keep going to school, the following sub-question were being asked: What inspires you to finish your study?; What influences youto earn an education? ; and Why you keep going to school? After series of coding of the responses of the participants of the study, only one theme emerged: "The significant others."

\section{Theme: The Significant Others}

During the in-depth interview and focus group discussion, the participants have shared that people who are very close to them are the reasons why they continue to go to school. Some of the participants attributed their motivation in going to school to their family such as their parents, either the mother or the father, siblings or family as a whole.

Lastly, friends can be one of the motivations of students to go to school. This provides companionship as well as help to a student. According to the two participants:

Research Question No. 3: What discourages you to be actively involved in classroom processes?

After series of analysis on the responses of the participants, the following themes emerged: "Lack of Sleep, 
Home Issues, Teacher Qualities, Unfriendly Learning Atmosphere, Difficulty in English Language and Mental Ability.

\section{Theme One: Lack of Sleep}

Some of the participants were not participative in the classroom because they are tiredand exhausted because they are working to support their study as well of their family.

\section{Theme Two: Home Issues}

There were some students who attributed their non-participation to classroom activities to their respective homes. The condition in the home affected their attitude in theclassroom.

\section{Theme Three: Teacher Qualities}

Some students had shared that their participation inside the classroom was dependenton the teacher. If the teacher is good they will listen and cooperate; if not, then they will not participate and even sleep during the lesson

The participation of students in class activities is dependent on the kind the personal and professional qualities of teachers. As reflected on the above statements, students are bored in class due to how teacher speaks. The participants found it unattractive if teacher is very serious to his lesson and the voice is not audible enough to be heard. Furthermore, some teachers, failed to integrate the lesson to real life. This will also result to boredom among students.

\section{Theme Four: Unfriendly Learning Atmosphere}

Some of the participants considered having an unfriendly environment as a hamper their participation in class. This situation can aggravate the problem of less engagement inside the classroom since some students were shy to participate.

\section{Theme Five: Difficulty in English Language}

On the other hand, students were not active in class discussion because they have difficulty in understanding the lesson, especially when English was used as medium of instruction. This revelation of the participants blamed their non-participation in theclassroom to the utilization of English as medium of instruction in most of academic subject both in junior and senior high school. The desire to learn and comprehend the lesson is present, but the difficulty in understanding terms and concepts discouraged them to participate in the classroom processes.

\section{Theme Six: Student's Mental Ability}

Some participants attributed their attitude to their mental ability. They did not participate in the classroom activities because they did not understand the lesson. They did not know the lesson that's why they were not active in the teaching and learning process.

\subsection{Discussion and Conclusion}

This chapter presented the discussion, conclusions, implications for practice and implications for future research based from the themes developed during the data analysis.

The purpose of the study was to describe the perception of less - motivated students about schooling. It aimed to understand deeper by uncovering the factors that resulted to less-engagement of students to learning activities in the classroom.

\section{Motivating Themes}

\section{Security of the Future}

Less - motivated students continued going to school and desired to finish their high school education because they recognized the importance of education as the way to secure a better future. They refused to join other students to cut classes or be a truant because they realized the value of education in finding work and employment. All of them believe that education is very important to have a better life (Zhou 2007) and would ensure equality of opportunity to all. Atuhurra (2014) supported the perception of these students that cognitive learning is very important for the future earning; Smith (2011) it will lead to a better job; Friels (2016) it is a way so that they can go to college and get a career where they can provide their needs and of their families. 
These findings may change the attitude of teachers towards this type of students. Teachers should have sympathetic attitude to this kind of students as their support of their desire to gain education. They may perceive that these students are less interested in schooling, but with the fact they keep going to school because of the belief that they can havegood future. Teachers should show empathy towards these kinds of students.

\section{The Significant Others}

The low motivated students continued to go to school despite of having low grades and difficulties they encountered in their studies because they were inspired by their parents, family and friends. Despite of the hardships experienced by the participants, they continued to go to school because of their family who influenced them to obtain it (Aanyaka, 2017 and Erlendsdótti, 2010). Others wanted to be a role model to their sons and future family (Smith 2011). The strong desire to be imitated in the future by their children provided strong motivation to some students. One of the participants declared that he liked school because hegot many friends. The claim was similar to the findings of Brickhouse, Lowery and Schultz (2000) on their study among African American female students in a public school and their academic achievement. They found out that the low achievers were more focus on their social groups such as friends. Thus, friends are helpful to these students because they can be the source of help in times of need.

\section{De-Motivating Themes}

\section{Lack of Sleep}

The participants of the study divulged that lack of sleep is one of the culprits that hampered their participation in class. Sleep is very vital to each person because it renews and revitalizes each organ of the body after whole day of activity. A good night's sleep isincredibly important to one's health as important as eating healthy and exercising (Reasons Why Sleep is Important_All high school students need to have at least $8-10$ hours of sleep (Sleep and School) Students attributed their problem to lack of sleep to internet addiction, staying late at night watching television and some of them were working students. Because of this condition, it is expected that the participation of students in classroom processes will most likely be affected and eventually affect their academic performances. The participants stated that they could not sustain attention in their classes because of lack of sleep. This is one of theeffects if a person is deprived of sleep. (Sleep and School) Because of this problem, the academic performance of the students will be affected (Hampton, 2005, Gikunda, et.al, 2014 n.d.; and Hamed, et.al. 2015.

Hill (2010) further pointed out that lack of sleep is one of the emotional and cognitive influences of students before coming to school with which hampered their engagement in classroom processes. However, teachers need to remember, that not all students who are sleepy in class are caused by internet addiction, but some are working students who are working at night. It is a very sad situation of which teachers have to consider in dealing with this type of students.

\section{Home Issues}

Some of the participants of the study disclosed that their home experiences are the reasons why they are not participative in class activities. One of the participants said that before going to school, his parent scolded him. According to him, he had bad mood in school and even thought of cutting classes. According to Lehman (2014) students who have shown a bad mood at school usually have conflict with either parent. And this student will have great temptation to misbehave (Sacks, 2016). Yelling and scolding of children will result to the decrease of academic performance (Barber 2014 and Pickering and Hong 2015); and ignoring their parents (Greenberg, 2012). However, if students were shown positive care and attention they are most likely to succeed in school as well as in life (Kobe University, 2016).

The other student said that doing household chores prevented him to spend time working with his projects and studying his lessons. Doing household chores also contributed to the factors why students are less engaged in the classroom. Students may find limited time to study and work on projects and assignments because of the assigned household chores. Doing household chores has impact on the study of the students according to Chowdurry (2015); Reich (2013); Emmanuel (2015). It decreases their academic performance as the result of their less engagement in learning processes.

\section{Teacher Qualities}

Some students are bored with the lesson because the voice of the teachers is too soft and are too serious. Students could not see the usefulness of the lesson to life. Teachers need to be engaging to hold the attention of the students. (Top 10 qualities of a great teacher). He might crack joke to sustain the interest of 
the students. Teachers need also to integrate lesson to life so that students can see the practical usefulness of the lesson (Groves and Welsh 2010). The integration of lesson to life is very important skill that a teacher should possess as reflected in the Philippine Professional Standard for Teachers. This is to allow students to see the connection and application of the lesson to life. In the study of Kacerja (2012) entitled "Real - life contexts in Mathematics and Students' Interest: An Albanian Study," he foundout that students preferred real-life situations to be used in Mathematics to see the connection of the subject to real world. According to the study making computer games, planning journeys, being productive in doing tasks, development of community, health matters, recreation and sports, construction\& engineering (boys) and designer clothes (girls) were the top real-life context preferred by Albanian students. These findings pointed out the necessity in integrating lesson to real-life situation to sustain the interest of the students.

\section{Difficulty in English as Medium of Instruction}

Students find difficulty in focusing their lesson and participate in classroom process because of their difficulty in understanding English terms and concepts. This problem was expressed by Grade 12 SMAW students who affirmed that they were interested to learn but the utilization of English as medium of instruction contributed their discouragement to actively participate in the classroom. The students wanted their teachers to simplify some terms for them to understand the lesson. These sentiments of the students were similar to the findings of Galloway (2017) in her study that students also wanted teachers to adapt and simplify the content of the class according to their English level.

In the study of Domingo (2015) on Area Effectiveness: English vs Filipino, students preferred Filipino in teaching Math because teachers are fast in explaining, details are not well presented and some words used by teachers cannot be understood. They even wanted to mix Filipino and English for better learning. In the study of Gorgonio (2012) on the "Use of Filipino and English in Social Studies Learning" he found out that there was no significant difference on the performances of the students. However, the performance of students utilizing English belonged to average level but belonged to the lower limit, while the performance of students utilizing Filipino was still in average level but in the upper limit. Lack of participation of students to subject using English as medium of instruction can be attributed to the difficulty of student in the English language (Magulu, 2016). He further advised the teachers need to teach children with the familiar language.

\section{Unfriendly Learning Environment}

Students were apprehensive to participate in classroom discussion because they were afraid that they will be bullied in the classroom if they gave wrong answers. This problem displayed a very unfriendly learning atmosphere which will not promote studentsparticipation in classroom activities. A classroom with lack of respect to students' view hampers participation (Susak, 2016). Since the fear of embarrassment contributed to less participation of students in the classroom (Reddington and Canada 2006), it is the jobtherefore of teachers to provide a learning atmosphere that will elicit participation from the students. There were participants of the study who claimed that they were of a shy-type individual. This called for urgency for teachers to be skillful in classroom management (State 2017) because self - confidence is a major contributing factor to class participation (Susak, 2016). Students will become more participative and interested in the lesson if the teachers create a safe and trustful environment. (Reis da Luz 2015 and Turano, 2005). In the study of Principe (2005) internal factors such as classroom environment is very influential to the academic performance of students. Thus, classroom environment played a crucial role in keeping students engaged and allowing them to be successful within the classroom (Hannah, 2013 and Reddington and Canada, 2016). Teachers should take effort to improve the participation of students because classroom participation is very important to students for them to develop their communication skills, confidence, enjoy their schooling and for their academic development (Linsin, 2017).

\section{Mental Ability}

Some of the participants refused to participate in classroom processes because they did not know or understand their lesson. This can attribute to their innate mental ability. Mental ability is one of the factors that contribute to the differences among learners. This refers to the capacity of the learner to understand and assimilate information for their own useand application (Corpuz and Salandanan, 2013). Mental ability can categorize students into superior, above average, average and below average. These differences should be considered by teachers in teaching the students. Wile (n.d.) stated that intellect or the mental ability affects learning. Some students find the lesson hard to understand because of their innate intelligence. In the study of Bulasito, et.al (2000), they found out that that mental ability was positively associated with academic success among 409 psychology students. Mondal, P (n.d.) also pointed out the close relationship between level and the success in the schoolwork. Therefore, teachers need to 
accept and understand that some students have difficulty inprocessing information presented to them. They need to take time to process the information for the students to understand better and may participate in classroom processes.

\title{
2.7 Implications for Educational Practice
}

This study tried to provide clearer picture on how the less motivated students perceived schooling so that teachers and school administration will fully understand their behavior in which at first look seemed irritating and annoying. After thorough analysis to theresponses of the participants of this investigation, the students have spoken their view about education which provided implication to education practice.

This study provided realization to all teachers, that the less - motivated students had recognized significance of education as the avenue to access better future. Despite of their low academic performance, they too struggled to earn the high school diploma because they valued education so much. Thus, teachers should recognize the presence of the students in the classroom because it is a manifestation that they value education despite of their outward attitude that seemed to be like they don't care about their studies.

This investigation further informed the teachers that they need to make necessary adjustment in the delivery of the curriculum for the students to be encouraged to be active in teaching and learning processes. First, they need to simplify English terms and concepts for better learning of students. There should be unlocking of difficulties. Second, teachers whosemedium of instruction is English should not talk too fast for the students to grasp clearly the lessons. Third, they need to provide psychological learning atmosphere conducive for learning and promote the culture of respect among students. Fourth, they should take effort inintegrating the lesson to real-life situations for the students to see the usefulness of the lesson. Fifth, they need also to improve the delivery of the lesson through modulated voice and having a sense of humor. And lastly, they need to accept that students have different levels of mental ability that they need to respect and accept to have a better attitude towards students who were not good at their respective subject.

This study has also implication to parents. They have significant contribution in improving the academic performance of their children. First and foremost, monitor the sleeping hours of their children because this is one of the culprits why students are not participative in the classroom. Second, avoid nagging and scolding their children before going to school. Lastly, do not give too much household chores to their children.

This investigation provided information to school administrators that there is a need toremind the teachers again the basic skills in the delivery of instruction. These included the providing positive learning atmosphere, unlocking of difficulties, respecting students' mental ability, developing a sense of humor and integrating lesson to life.

This study can be used by the Panabo City Division of Panabo in recommending for a passage of law prohibiting high school students to enter internet cafes beyond 10:30 in the evening because it affects the performance of students in school.

This study can be the basis of the Local Government Unit of Panabo City to support the recommendation of Panabo City Division in restricting high school students to enter internet café's beyond 10:30 in the evening.

This study will be the basis of the Department of Education to classify students according to their level of language proficiency for the teachers to design strategies and use language appropriate to their level.

\section{ACKNOWLEDGEMENT}

This research was funded by the Basic Education Research Fund (BERF) of the Department of Education, Region XI, Philippines in 2019.

\section{REFERENCE LIST}

\author{
Amlaner, B. (2015) School Climate Study in Greater Alanta Schools of the Georgia-Cumberland \\ Conference. Retrieved June 18, 2018 from \\ https://digitalcommons.kennesaw.edu/cgi/viewcontent.cgi? \\ referer=https://www.google.com.ph/\&httpsredir $=1$ \&article $=1682 \&$ context=etd
}


Proceedings of INTCESS 2022- 9th International Conference on Education \& Education of Social Sciences 17-18 January 2022- Online Conference

Anyaka, S. (2017) Motivation of African American Students to Persevere Academically. Retrieved June 10, 2018 from

https://scholarworks. waldenu.edu/cgi/viewcontent.cgi?article=4529\&context=dissertations

Atuhurra, J. (2014) An Empirical Analysis of the Impact of the Universal Primary Education Policies on Educational Performances in East Africa: A Comparative Study of Uganda's Upe and Kenya's FPE. Retrieved June8, 2018 from http://www.grips.ac.jp/cms/wpcontent/uploads/2014/11/fulltextphd11201.pdf

Barber, N. (2014). Blaming Parents for their Children's Failings. Retrieved June 11, 2018 from https://www.psychologytoday.com/us/blog/the-human-beast/201402/blaming-parents-their-childrensfailings

Brickhouse, N. Lowery, P. Schultz K. (2000). Empowering groups for academic success: An innovative approach to prevent high school failure for at risk African American Girls. Journal of Professional School Counseling 8(5) 377-390. DOI: 10.1002/(SICl)1098- 2736

Busato, V.; Prins, F. ; Elshou, J.; Hamaker, C. (2000). Intellectual ability, learning style, personality, achievement motivation and academic success of psychology students in higher education. RetrievedJuly 6, 2018 from https://www.sciencedirect.com/science/article/pii/S0191886999002536

Certo JL' Cauley KM, and Chafin C. Students' perspectives on their high school experience.

Retrieved June 10, 2018 from https://www.ncbi.nlm.nih.gov/pubmed/15053496

Chowdurry, S. (November 2015). Spending Time on Domestic Chores can Impact Education, Finds Study. Retrieved July 12, 2018 from http://timesofindia.indiatimes.com/articleshow/49886435.cms?utm_source=contentofi nterest\&utm_medium=text\&utm_campaign=cppst

Coyne, A. (2012)The Relationship Between Perceptions of School Climate and Student Achievement in Schools That Use Jostens' Renaissance Programs Amy Yarborough Coyne Retrieved June 15,2018 from https://aquila.usm.edu/cgi/viewcontent.cgi?article=1426\&context=dissertations

Creswell, J. (2009). Research design: qualitative, quantitative and mixed method approaches $3^{\text {rd }}$ ed. Sage Publication, California.

Domingo, D. (2015)Content Area Effectiveness: Englsh vs Filipino. Retrieved June 16, 2018 from https://www.researchgate.net/publication/299477353_content_area_effectiveness_eng lish_vs_filipino_medium_of_instruction

Ellwood, 1993, p. 77. Cited by Murphy, J. (2016)Understanding Schooling Through the Eyesof Students. RetrievedJune 24, 2018 from https://books.google.com.ph/books?id=1193CwAAQBAJ\&pg= PA2118\&lpg=PA2118\&dq=how+students+perceive+schooling\&source=bl\&ots=nKhXr7ld84\&sig=Lfan WHYH24MgtYO7HnDnnsfskY\&hl=en\&sa=X\&ved=0ahUKEwjhvvvjicLWAhVMH5QKHbGC

BUU4UBDoAQgwMAl\#v=onepage\&q=how\%20students\%20perceive\%20schooling\&f=false

Engelland - Schultz, J. (2015) Longitudinal Effects of School Climate on MiddleSchool Students' Academic,Social-Emotional and Behavioral Outcomes. Retrieved June 24, 2018 from

https://ir.library.illinoisstate.edu/cgi/viewcontent.cgi?referer=https://www.google.com

.ph/\&httpsredir=1\&article $=1441 \&$ context=etd

Emmanuel, L. (2015) the influence of household chores on girls' academic performance insecondary schools in morogoro rural district Retrieved June 25, 2018 from http://repository.out.ac.tz/1408/1/Lydia-EMMANUEL-DISSERTATION-19-11- 2015.pdf

Erlendsdotti, G. (2010) Effects of Parental Involvement in Education A Case Study in Namibia. Retrieved June 21, 2018 from https://skemman.is/bitstream/1946/6925/1/MEd\%20thesisGu\%C3\%BOlaug.pdf

Friels , A. (2016) Motivation Towards Success: A Qualitative Comparative Case Study Illustrating The Differences In Motivating Factors In Achievement Between Low Ses High Achieving And Low Achieving African American High School Females Retrieved June 19, 2018 from 
https://scholarcommons.sc.edu/cgi/viewcontent.cgi?article=4453\&context=etd

Fuberg, E. (2010) How do students' perceptions of their education change over time? - exploring perceptions of learning, responsibility, engagement and satisfaction. Retrieved June 18, 2018 from . https://www.divaportal.org/smash/get/diva2:419082/FULLTEXT01.pdf

Galloway, N. (2017)How effective is English as a medium of instruction (EMI)? Retrieved June 19, 2018 from https://www.britishcouncil.org/voices-magazine/how-effective-english-medium- instructionemi

Gikunda, R; Abura, G.; Kiriungi,L. and Muchiri, J. (2014). The Effect of Sleep Quantity on Performance of Students in Public Universities, Kenya. http://meritresearchjournals.org/er/content/2014/June/Gikunda\%20et\%20al.pdf

Gorgnio, J. (2012) Use of Filipino and English in Social Studies Learning. https://www.researchgate.net/publication/317231828_USE_OF_FILIPINO AND_EN GLISH_IN_SOCIAL_STUDIES_LEARNING

Greenberg, M. (2012). Nagging and Giving Multiple Warnings. Retrieved June 24, 2018 from https://www.psychologytoday.com/us/blog/the-mindful-self-express/201209/worst- mistakes-parentsmake-when-talking-kids

Groves and Welsh (2010) Issues in Educational Research. The high schoolexperience: What students say. Retrieved June 23, 2020 from http://www.iier.org.au/iier20/groves.pdf.

Hill, P. (2010). Student Engagement and Student Voices Retrieved June 21, 2018 from https://cdr.lib.unc.edu/indexablecontent/uuid:76d8b87d-761a-441a-a5dd- 2c3c52127303

Reich, J; Hein, S; Krivulskaya, S.; , L.; and Grigorenko, E. (2013). Associations between household responsibilities and academic competencies in the context of education accessibility in Zambia. Retrieved June 24, 2018 from https://www.ncbi.nlm.nih.gov/pmc/articles/PMC3859459/

Kacerja, S. (2012). Real-life contexts in mathematics and students' interests An Albanian study. Retrieved June 21, 2018 from https://brage.bibsys.no/xmlui/bitstream/handle/11250/138125/Kacerja_2012_Real.pdf?sequence=1

Kobe University. (2016, June 17). How your parenting style affects your child's future. Science Daily. Retrieved September 22, 2018 from www.sciencedaily.com/releases/2016/06/160617082522.htm

Konings, K. (2007) . Student Perspective on EducationL Implications for Instructional Redesign. Retrieved June 18, 2018 from https://dspace.ou.nl/bitstream/1820/1042/1/Dissertation\%20K\%C3\%B6nings\%20200 7.pdf

Lehman, S. (2014) Conflicts at Home and School Affects Teens at School and Vice Versa.Retrieved June 17, 2018 from https://www.reuters.com/article/us-health-psychology-teen-development/conflictsat-home-affect-teens-at-school-and-vice-versa- idUSKBNOIK1NM20141031

Linsin, M. (2017) Why Students Don't Participate In Discussions And What To Do About It.Retrieved June 21, 2018 from https://www.smartclassroommanagement.com/2017/02/11/why-students-dontparticipate-in-discussions-and-what-to-do-about-it/

Magulu, H. (2016) The Impact of the Languages of Instruction on Teacher-Pupils Classrooom Interaction in History Subject in Primary Schools in Tanzania. Retrieved June 17, 2018 from https://www.duo.uio.no/bitstream/handle/10852/52390/Hamisa--Thesis.pdf

Marzano, R. (2017). Different Kind of Classroom. Retrieved October 20, 2017. Retrieved from http://www.ascd.org/publications/books/61192107/chapters/Dimension-1@- Positive-Attitudes-andPerceptions-About-Learning.aspx

Maykut, P. and Morehouse, R. (1994). Beginning qualitative research. A philosophical and practical guide. The Falmer Press, Washington D.C.

Mondal, P. (n.d). Seven Important Factors that May Affect the Learning Process. Retrieved June 27, 2018 from http://www.yourarticlelibrary.com/learning/7-important-factors- that-may-affect-the-learningprocess $/ 6064$

Murphy (2016) Understanding Schooling through the Eyes of Students. Retrieved October10, 2017. 
Retrieved fromhttps://books.google.com.ph/books?id=1193CwAAQBAJ\&pg=PA2118\&lpg=PA211

$8 \& d q=h o w+$ students+perceive+schooling\&source=bl\&ots=nKhXr7ld84\&sig=LfanW

HYH24MgtYO7HnDnnsfskY\&hl=en\&sa=X\&ved=0ahUKEwjhvvvjicLWAhVMH5

QKHbGCBUU4UBDoAQgwMAl\#v=onepage \&q=how\%20students\%20perceive\%20schooling \& $f=f a l s e$

Neale, P. and Boyce, C. (2006). Conducting in-depths interviews: A guide for designing and conducting indepth interviews for evaluation input. Retrieved December 21, 2012 from http://www2.pathfinder.org/site/DocServer/m_e_tool_series_indepth_interviews.pdf

Nonaka, D.; Gunawardena, N; Indrwanasa, S; Nanri, A; Rajapkse, L; Mizoue, T and Samarasinghe, D. (2010) Students' perception of school environment and life satisfaction at Sinhala-medium secondary schools in the Colombo District, Sri Lanka. Retrieved June 25, 2018 from https://www.ncbi.nlm.nih.gov/pubmed/23413721.

Ospina, S. (2004). Qualitative research. Encyclopedia of leadership. Retrieved March 4, 2013 from http://www.wagner.nyu.edu/leadership/publications/files/Qualitative_Research.pdf

Pickering , J. and Hong, J. (2015). If you want your child to bring home better grades, stop yelling and try this, Retrieved June 18, 2018 from http://theconversation.com/if-you- want-your-child-to-bring-homebetter-grades-stop-yelling-and-try-this-48975

Polkinghorne, D. (2005). Language and meaning: Data collection in qualitative research. Journal of Counseling Psychology. Retrieved February 3, 2012 from http://www.usc.edu/projects/rehab/private/docs/researchers/ polkinghorne /3_polkinghorne.pdf

Pratt, N. (2006). Qualitative research. Retrieved September 2012 from http://www.edu.plymouth.ac.uk/resined/Qualitative\%20methods\%202/qualrshm.htm

Principe, H. (November 2005)Factors Influencing Student's Academic Performance in the First Accounting Course: A Comparative Study Between Public and Private University in Puerto Rico. http://ponce.inter.edu/cai/tesis/hrodriguez/index.pdf

Reis da Luz, F. (2015)the relationship between teachers and students in the classroom: communicative language teaching approach and cooperative learning strategy to improve learning Retrieve on June 19, 2018 from https://vc.bridgew.edu/cgi/viewcontent.cgi?referer=https://www.google.com.ph/\&htt psredir $=1$ \&article $=1020 \&$ context=theses

Reddington, C. and Canada, R. (2006). How Does Student Participation Influence Students Achievement. Retrieved June 18, 2018 from https://steinhardt.nyu.edu/teachlearn/research/action/participation_achievement

Ronda, R. (2004) DepEd Promoting English as Medium of Instruction. Retrieved June 23, 2018 from https://www.philstar.com/headlines/2004/07/19/258044/deped-promoting- english-medium-instruction

Sacks, J. (2016) Scolding and Reprimanding as Part of Child Discipline: The Benefits Versus the Risks Retrieved June 9, 2018 fromhttps://www.tribecaplaytherapy.com/blog/2016/5/9/scoldingand reprimanding-as-part-of-child-discipline-the-benefits-versus-the-risks

Susak, M. (2016). Factors that Affect Classroom Participation Retrieved June 23, 2018 from https://scholarworks.rit.edu/cgi/viewcontent.cgi?referer=https://www.google.com.ph/ \&httpsredir $=1$ \&article $=10526 \&$ context=theses

Weinstein, R. (1983). Student Perception of Schooling. The Elementary School Journal, 83(4), 287-312.

Wichaikul, S. (2013). Qualitative Data Collection. Retrieved January 21, 2013 from http://www.slideshare.net/susheewa/qualitative-data-collection-14057399

Yeo, J. (2015) When family problems affect children in school. Retrieved June 8, 2018 from https://www.schoolbag.sg/story/when-family-problems-affect-children-in-school

Zhou, Y. (2007). Success for All: A Comprehensive Educational Reform for Improving at - risk Students in an Urban School in China. Retrieved June 13, 2018 from https://pdfs.semanticscholar.org/bd5f/f1388d32186d17293fe44b9365ce0e5660e9.pdf

Yue, Y. (2017)the impact of positive school experiences and school ses on depressive symptoms in chinese children: a multilevel investigation. Retrieved October 4, 2018 from: 
https://www.researchgate.net/publication/319323241

Turano, A. (2005) The impact of classroom environment on student learning. Retrieved June10,2018 from https://rdw.rowan.edu/cgi/viewcontent.cgi?article=2089\&context=etd

Wile, Elise. (n.d.). Factors That Affect Individual Learning. Synonym. Retrieved from Retrieved June 21, 2018 from https://classroom.synonym.com/factors-affect-individual-learning-8207913.html

Reasons Why Sleep is Important Retrieved June 17, 2018 from https://www.healthline.com/nutrition/10reasons-why-good-sleep-is-important.

Student Perception of School. Retrieved June 10, 2018 from http://nrcgt.uconn.edu/wpcontent/uploads/sites/953/2015/07/sp_printversion.pdf. 